\title{
ASSESSMENT OF SOLAR ELECTRICITY POTENTIALS IN NORTH AFRICA BASED ON SATELLITE DATA AND A GEOGRAPHIC INFORMATION SYSTEM
}

\author{
Hartmut Broesamle $\dagger$, Hermann Mannstein + , Christoph Schillings $* \dagger \ddagger$ \\ and Franz Trieb*
}

\author{
+Institute of Atmospheric Physics \\ DLR Oberpfaffenhofen \\ D-82234 Weßling, Germany
}

\author{
*Institute of Technical Thermodynamics \\ DLR Stuttgart \\ Pfaffenwaldring 38-40 \\ D-70569 Stuttgart, Germany
}

\author{
$\dagger$ NEVAG / Enersys GmbH \\ Rheingaustr. 184 \\ D-65203 Wiesbaden
}

\begin{abstract}
Solar thermal power plants will provide a major share of the renewable energy sources needed in the future. STEPS, an

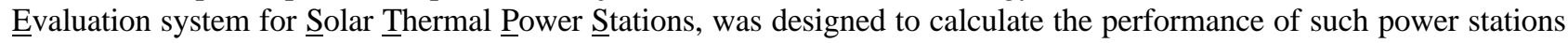
as function of direct solar radiation, geographical conditions (land slope, land cover, distance from cooling water resources, etc.), infrastructure (pipelines, electricity grids, streets etc.) and the configuration and performance of a selected solar thermal power plant concept. A cloud index derived from METEOSAT satellite images is used to calculate the direct solar radiation resource. A geographic information system (GIS) is used to process all the parameters for site assessment. In order to demonstrate the concept, an analysis of Northern Africa was performed with STEPS providing a ranking of sites with respect to the potential and cost of solar thermal electricity for a particular power plant configuration. Results were obtained with high spatial and temporal resolution.
\end{abstract}

\section{Keywords}

Solar electricity cost, geographic information system, solar energy, North Africa, solar radiation

\section{Introduction}

Solar thermal power plants use concentrated solar radiation in order to generate high pressure steam for electricity generation in conventional steam turbines. Because fuel is substituted by solar collectors, an additional investment and additional space at the plant site is required. The evaluation tool STEPS allows the selection and ranking of sites for solar thermal power plant construction, analysing a large region, country or even a continent (2). Among others, the following services can be provided by STEPS:

- Maps of the direct normal irradiation (DNI) resource in high spatial and temporal resolution (best resolution: $2.5 \mathrm{~km}$ x $2.5 \mathrm{~km}$, hourly mean values).

- Assessment of the technical and economic potential of solar power generation in a defined region.

- Ranking and selection of sites for the construction of solar thermal power stations.

- Providing the basis for solar power build out scenarios.

- Sensitivity analysis of the performance of solar thermal power stations regarding site conditions.

STEPS has a clear modular structure (Figure 1). The main module defines the interaction of all other modules. Temporal and spatial resolution can be varied according to specific needs. Results are typically shown as maps using a geographic information system (GIS). The first application of STEPS was the estimation of the potential and present cost of solar thermal power plants in North Africa. The following topics were treated within the study:

- Determination of the geographical and meteorological frame conditions.

- Determination of all suitable sites for the construction of solar thermal power plants.

- Development of a map of the direct normal irradiation (DNI) for North Africa.

- Calculation of the solar electricity yield per $\mathrm{km}^{2}$ of land.

- Calculation of power generation costs per $\mathrm{kWh}$.

The procedure and the results of this analysis are described in the following.

\footnotetext{
$¥$ former affiliation: Geographical Institutes of the University of Bonn, D-53115 Bonn

Corresponding author e-mail address: Franz.Trieb@DLR.de
} 


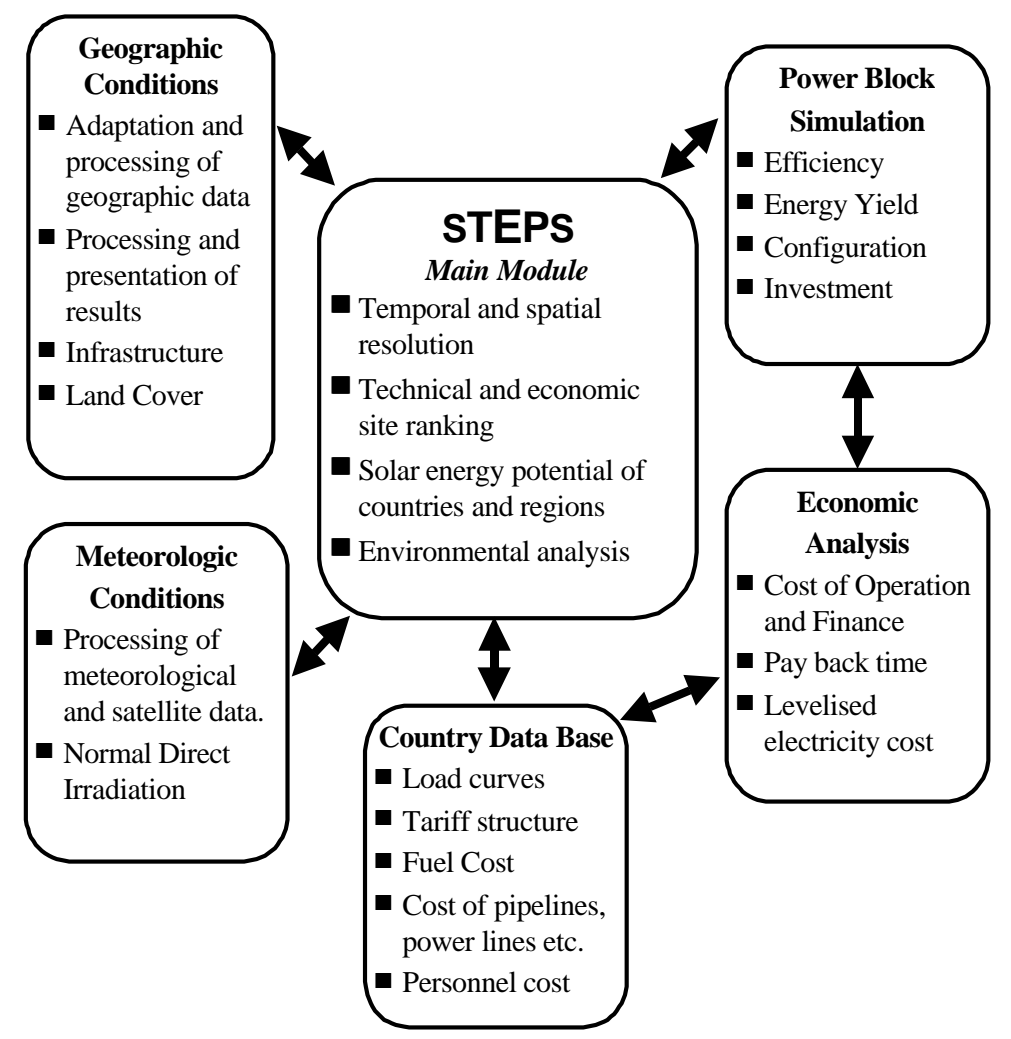

Figure 1: The modular structure of STEPS

\section{Assessment of the Geographic Frame Conditions}

All available data sets (satellite data, digital maps etc.) are processed in a Geographic Information System (GIS). The usually heterogeneous data sets have to be transferred into a uniform geographic projection and data format. Important data for the ranking and evaluation of potential sites of solar thermal power plants are e.g. land use, land cover, slope and water surfaces.

Solar thermal power stations have a relative big area demand in comparison to conventional power stations. The specific area demand for a parabolic trough power station is approximately $1 \mathrm{~km}^{2}$ per $50 \mathrm{MW}$ of installed electric capacity. Typical sites are hot, dry regions like deserts or semi-deserts. Surface water, forests, settlements, arable and cultivated land are considered unsuitable for the construction of such plants. Sand deserts are not considered to be a criteria for exclusion, but may elevate the cost.

Land cover and land use data sets are created by the U.S. Geological Survey (USGS), the University of Nebraska-Lincoln (UNL) and the European Commission for Research Co-operation. These data can be obtained partially from the Earth Resources Observation System (EROS) Data Centre via the internet. For the determination of the land cover and land use, the global ecosystems classification by Olson (5) is used. A reduction to 10 classes of land cover has been applied.

The land slope should be less than $5 \%$ for parabolic trough plants. We used the digital elevation model (DEM) called GTOPO30 of the EROS Data Centre with a spatial resolution of nearly $1 \mathrm{~km} \mathrm{x} 1 \mathrm{~km}$ in order to calculate the slope. The data was considered to be acceptable for the first application of STEPS, but a land slope of maximum $2 \%$ instead of $5 \%$ was selected as threshold in order to compensate for the limited resolution. For more detailed project studies, more accurate DEM may be used, as e.g. the Shuttle Radar Topography Mission (SRTM) by NASA with a $30 \mathrm{~m}$ spatial resolution. The shading of mountains, especially in the morning and afternoon, can also be calculated with DEM data, but this feature has been neglected in the first application of STEPS.

Figure 3 shows some of the results of this analysis. In North Africa, $12.6 \mathrm{Mio} \mathrm{km}^{2}$ fulfil the criteria of suitability for the construction of solar thermal power plants with respect to land slope and land cover. 


\section{Solar Radiation Resource Assessment}

The most important parameter for the site selection of solar thermal power plants is the direct normal irradiation (DNI). The direct normal solar irradiation on the ground is described by:

$$
D N I=E_{0} \cdot\left(\tau_{R} \cdot \tau_{O z o n} \cdot \tau_{G a s} \cdot \tau_{W V} \cdot \tau_{A e}\right) \cdot \tau_{C l}
$$

$E_{0}$ is the extraterrestrial irradiation. $\tau_{R}, \tau_{O z o n}, \tau_{G a s}, \tau_{W V}, \tau_{A e}, \tau_{C l}$ are the transmittance functions for Rayleigh scattering, ozone absorption, absorption by uniformly mixed gas (oxygen and carbon dioxide), water vapour absorption, aerosol extinction and cloud extinction, respectively. The formula is based on the clear sky model of BIRD (1), (11). For calculating the DNI in STEPS, we have modified that model, adding a coefficient of transmission $\left(\tau_{C l}\right)$ that takes into account the attenuation of irradiation by clouds. We derive a cloud index from the visible (VIS) and infrared (IR) image channel of the METEOSAT weather satellite based on self adjusting, local thresholds which represent the spatial and temporal variation of the surface properties (4). We look at long time series of METEOSAT IR-data to achieve a local temperature threshold which is close to the temperature of the cloud-free surface. The reference temperature of land surface is described as a function of time for every pixel:

$$
T=a_{0}+a_{1}\left(\cos \left(\chi-a_{3}+\sin \left(a_{2}\right) \times \sin \left(\chi-a_{3}\right)\right)+0.1 \times \sin \left(\chi-a_{3}\right)\right)
$$

with $\chi=t / 24 \times 2 \pi$ and $t=$ decimal hours of the satellite (UTC). $a_{0}$ gives the daily mean temperature, $a_{1}$ the temperature amplitude, $a_{2}$ influences the width and steepness of the daily temperature wave and $a_{3}$ gives the phase shift, which is dominated by the local solar time. The coefficients $a_{n}$ are fitted for every daily period and every pixel using the fit from the former time interval and the corresponding new "cloud free" temperature.

We use the following differences of properties of clouds versus surface for a first cloud detection:

- Clouds are cold. The weight of every pixel with a temperature colder than estimated is reduced proportional to the difference.

- Clouds move. We compare the data to the previous image and the image of the day before. Clouds are colder and show up as local differences.

- Surface temperature has a regular daily variation and depends on the landscape. We compare the data to the predicted reference temperature image. Clouds again show up as local differences.

- Weather patterns have a larger scale than pixel size. We allow for deviations from the predicted temperatures if they are common within regions of pixels with similar surface properties.

For corrections of the visible channel of METEOSAT, we analysed one year of VIS data to extract the distribution of counts with respect to the solar zenith angle and the angular distance between sun and satellite seen from the surface. A further correction is made to account for atmospheric influences like forward and backward scattering within the atmosphere by defining and subtracting a minimum count from the satellite values (4). VIS data is included into the decision process at locations, where the cosine of the solar zenith angle is greater than 0.1 (the sun is more than $5.7^{\circ}$ over the horizon). Similar to the IR analysis, we derive a reference image, which is in this case not variable throughout the day. The VIS images are compared against the predicted image and the previous image. The corrected count has to be higher then a threshold derived from the predicted 'cloud free' scene.

Both IR and VIS information are combined to the final result by linear interpolation between the expected "cloud free value" and a threshold for a "fully cloudy" pixel $\left(-40^{\circ} \mathrm{C}\right.$ in the IR and a corrected count of 150 in the VIS channel). The higher of both values is given as result. The interpolation scheme and the values of these thresholds might be changed, if better validation data will be available. In a first rough assumption, the cloud-index is converted by a linear function into a coefficient of cloud transmittance.

Not only clouds, but also aerosols have an important influence on solar radiation. We use the Global Aerosol Data Set by KÖPKE et al. (3) to calculate the aerosol transmittance. This data set has a spatial resolution of $5^{\circ}$ $\mathrm{x} 5^{\circ}$ and a temporal resolution of two values per year (summer and winter). We took the Aerosol Optical Thickness (AOT) for the wavelengths $0.5 \mu \mathrm{m}$ and $0.35 \mu \mathrm{m}$ and for a relative humidity of $50 \%$. These wave- 
lengths are required by the BIRD aerosol transmittance function. We extended the summer values from June until November, the winter values from December until May (10).

The low resolution of the available aerosol data has been considered critical for our application. Therefore, aerosol transmittances were selected considering only those values relevant for the main areas of interest (deserts and semi-deserts). Furthermore, aerosol transmittance values were reduced by $20 \%$ for every 1000 meters of altitude, taking into consideration the reduced atmospheric turbidity at elevated sites. Values for water vapour and ozone are taken from the NASA Water Vapour Project (NVAP) and the NASA Total Ozone Mapping Spectrometer project (TOMS), respectively.

The direct solar irradiation obtained by this method shows good agreement ( $\pm 5 \%$ with respect to the annual mean) with data from selected sites derived from WMO-WRDC data, where DNI had to be calculated from global horizontal values using empirical conversion models (4). Measured direct radiation data is very poor in the regions in question, so we had to compare our results to hourly time series from 1998 measured in Almeria, Southern Spain. With respect to this high quality data set, we observed errors of less than $\pm 5 \%$ for monthly sums of DNI $(2,4,6)$. On hourly basis, the coincidence is very good for clear days, but unsatisfactory for cloudy days, although the general daily pattern and the daily sum of DNI is again represented quite well (Figure 2). Other data sets displaying one typical day per month in hourly resolution for Taroudant and Ouarzazate (Morocco), Ouwairah (Jordan), Tahrir (Egypt) and Tenerife (Spain) were compared to our results showing differences from $+5 \%$ to $-15 \%$ with respect to the annual sums of DNI (2). It must be mentioned that those data sets were obtained from rough estimates and did cover different time intervals, so the comparison does not necessarily show the quality of the satellite-derived data. All in all, the satellite data was more complete and had a much better coverage and resolution than the available ground measurements.

For the analysis of North Africa, METEOSAT images from 1998 were used for the calculation of the direct normal irradiation. STEPS calculates the DNI for every hour and every location (8760 values for each location) with a spatial resolution of approximately $5 \times 5 \mathrm{~km}$. These values are used by the power plant simulation module to determine the performance and energy yield. The results were also used to create a map of the yearly sums of solar direct normal irradiation for North Africa for 1998 (Figure 4). A long term climatology of solar radiation was not used within this study.

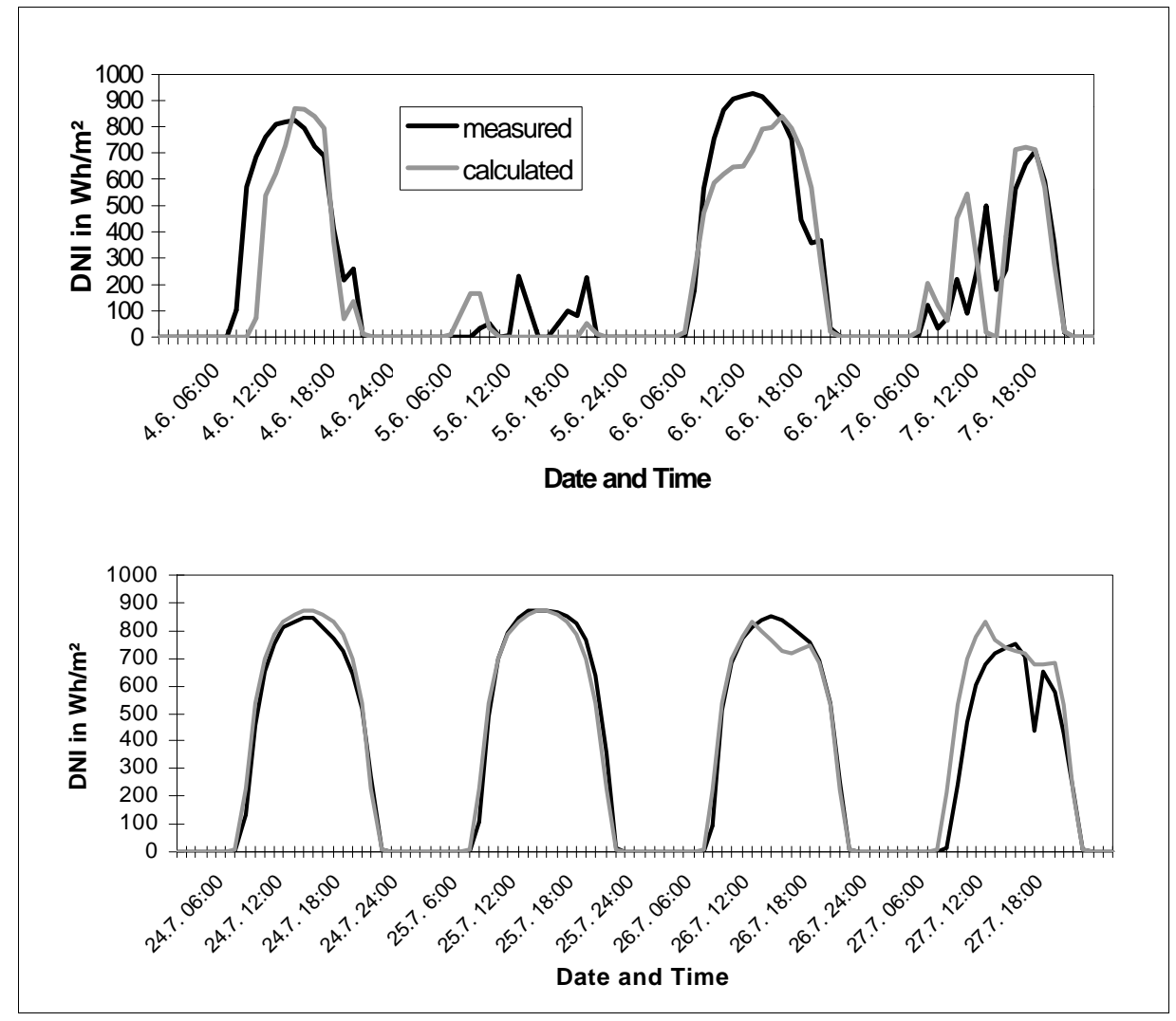

Figure 2: Measured and calculated direct normal irradiation on clear and cloudy days in Almeria, Spain (4). The ground measured data was kindly provided by Schlaich, Bergermann \& Partner, Stuttgart. 


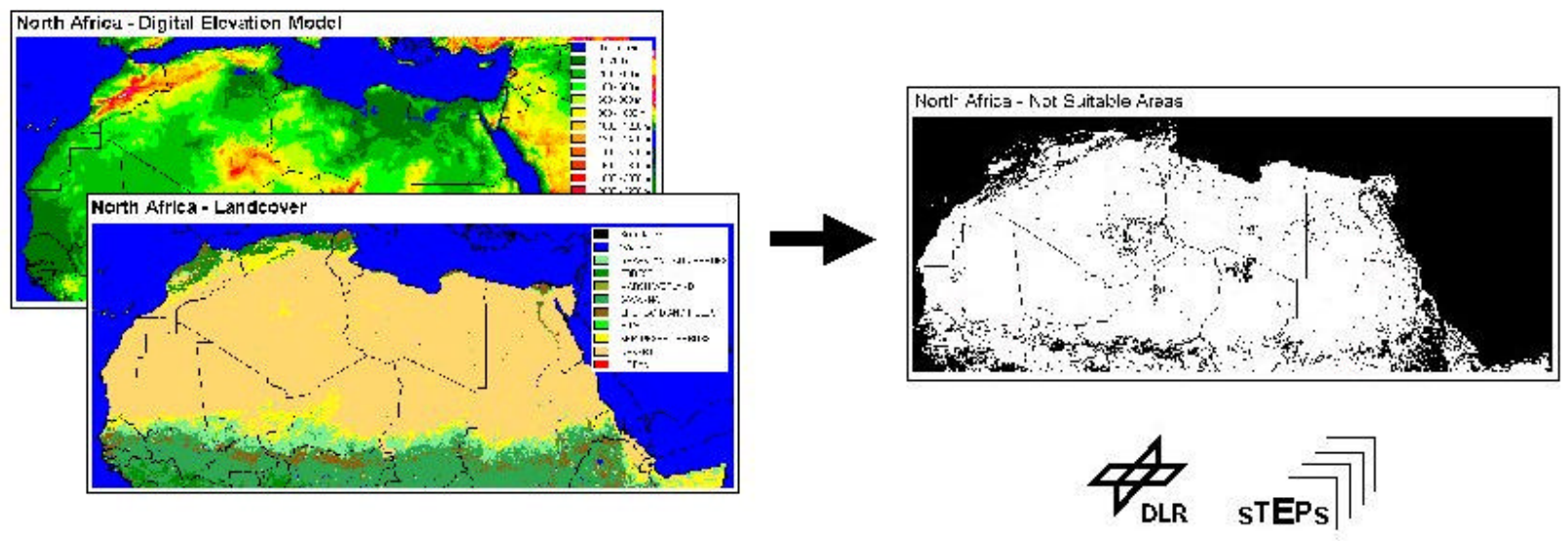

Figure 3: North Africa - Determination of geographic frame conditions and non-suitable (black) areas

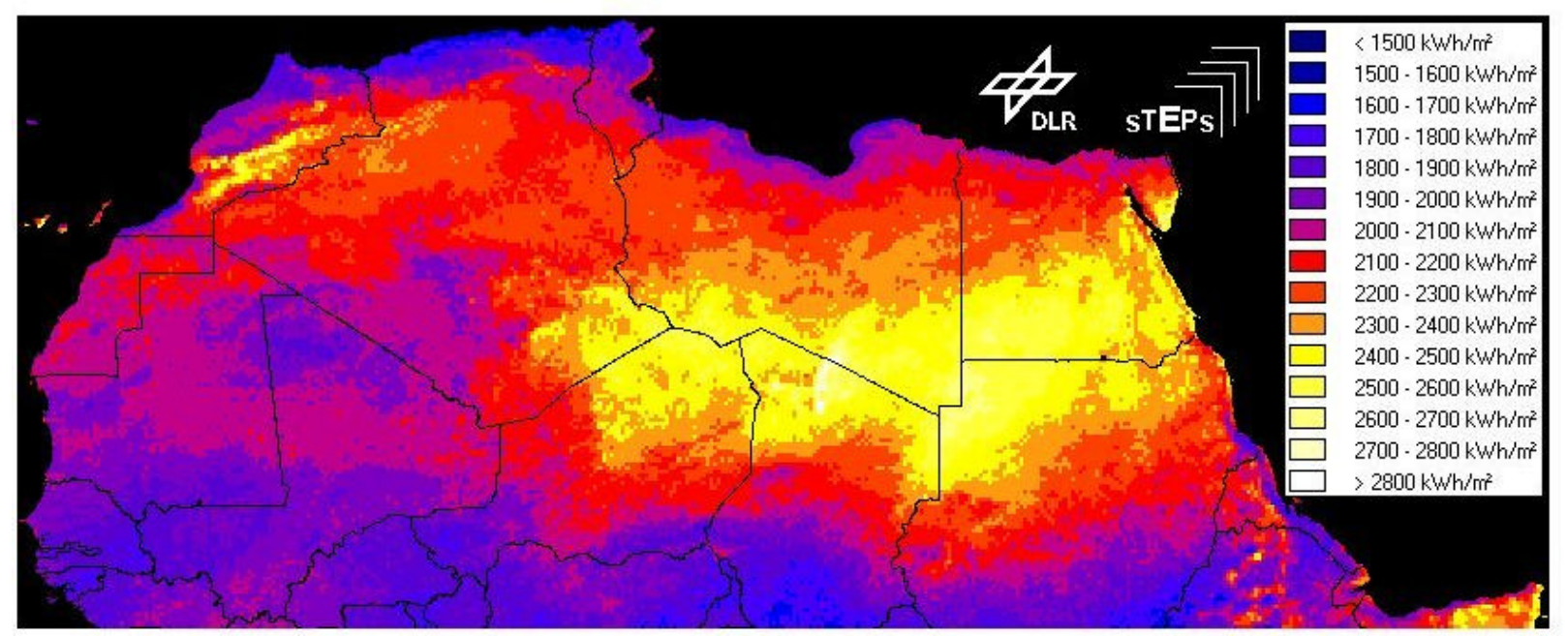

Figure 4: North Africa - Annual sum of Direct Normal Irradiation (1998).

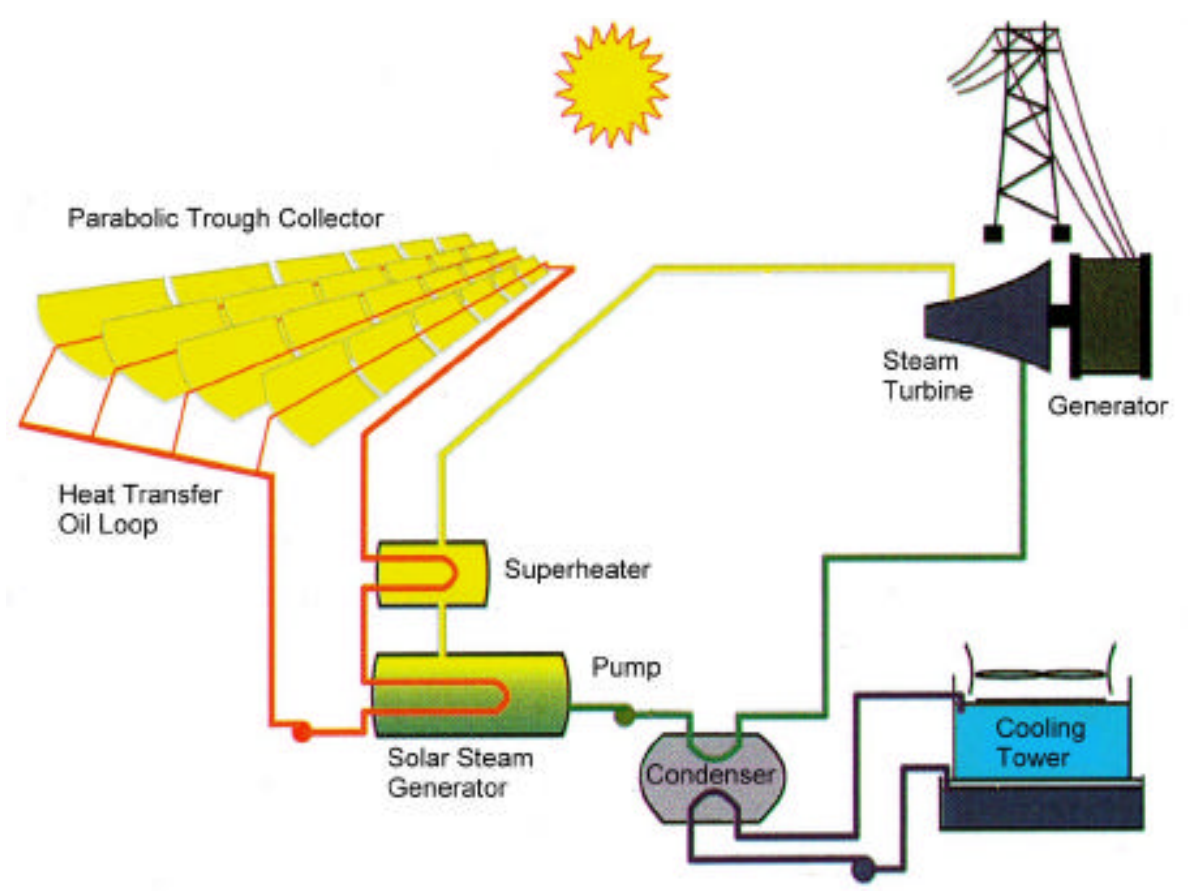

Figure 5: Basic solar thermal power plant configuration simulated by STEPS 


\section{Solar Power Plant Performance}

In the first prototype of STEPS, a solar power plant simulation model was integrated that represents a 200 MW parabolic trough solar electricity generating system (SEGS) in solar only operation mode and without thermal energy storage (Figure 5). The model is made up of two parts, one that simulates the energy balance of the solar field, and a second that represents the conversion efficiency of the Rankine steam cycle as a function of time. The module calculates the hourly thermal power output of the solar field and the electricity yield of the SEGS from the solar direct normal radiation generated in the meteorology module for each point of the map. For the simulation of the collector field energy output, a simplified stationary model of the physical properties and behaviour of the collector is applied. The physical parameters represent the LS-3 parabolic trough collectors installed in some of the plants in California (Table 1). A detailed description of the performance model and the related set of parameters can be found in (2).

A one-axis tracked parabolic trough collector shows certain losses that depend only on its geometrical structure and on the angle of incidence. The following geometric losses are considered in the model:

- Cosine losses represented by $\xi_{\mathrm{Cos}}$ consider the smaller active area of projection of the collector due to non-perpendicular irradiation.

- The incident angle modifier represented by $\xi_{\text {IAM }}$ considers the distortion of the reflected image of the sun at non-perpendicular incident angles.

- Collector end-losses are the portion of the sunlight that is reflected outside of the range of the absorber tubes at the end of each collector row. End losses are described by the intercept factor $\xi_{\mathrm{E}}$.

- Shading losses within the solar field are described by the shading factor $\xi_{\mathrm{s}}$.

The second important group of loss mechanisms are the optical losses that occur by non ideal reflection and absorption of solar radiation. The optical efficiency is described by the :

- reflectivity of the mirrors $\rho$,

- transmission factor of the mirror glass cover $\tau_{l}$,

- optical precision of the mirror surface (quality factor) $\gamma$,

- transmission factor of the glass tube that surrounds the absorber tube $\tau_{2}$,

- coefficient of absorption of the absorber tube $\alpha$.

The third group of loss mechanisms considers the thermal losses of the hot collector elements during operation. Losses caused by thermal convection are in a first approximation proportional to the difference of the mean surface temperature of the absorber tube $T_{\mathrm{A}}(653 \mathrm{~K})$ and the ambient temperature perceived by the absorber tube exposed to the sunlight $T_{\text {amb }}(330 \mathrm{~K})$, that both are assumed to be constant during operation. Convection losses are quantified by the convection loss factor $U\left[\mathrm{~W} / \mathrm{m}^{2} \mathrm{~K}\right]$. Thermal radiation losses are described by a term that is proportional to the difference of the same temperatures but to the power of four. The intensity of thermal radiative emission losses is described by the coefficient of emission $\varepsilon$ of the absorber tube surface and the Boltzmann constant $\sigma\left[\mathrm{W} / \mathrm{m}^{2} \mathrm{~K}^{4}\right]$. The simulation model yields the thermal power output of the solar field according to the formula:

$$
\dot{Q}_{\mathrm{SF}}=A_{\mathrm{SF}} \cdot D N I \cdot\left[\xi_{\mathrm{geo}} \eta_{\mathrm{opt}}-\frac{\pi \cdot U}{C \cdot D N I} \cdot\left(T_{\mathrm{A}}-T_{\mathrm{amb}}\right)-\frac{\pi \cdot \varepsilon \cdot \sigma}{C \cdot D N I} \cdot\left(T_{\mathrm{A}}^{4}-T_{\mathrm{amb}}^{4}\right)\right]
$$

with the collector area of the solar field $A_{\mathrm{SF}}$, the factor of concentration of the parabolic trough $C$, the direct normal irradiation DNI, the geometric efficiency $\xi_{\text {geo }}=\xi_{\text {IAM }} \xi_{\mathrm{S}} \xi_{\mathrm{E}} \xi_{\mathrm{COS}}$ and the optical efficiency $\eta_{\mathrm{opt}}=\alpha$ $\rho \gamma \tau_{1} \tau_{2}$ (Table 1).

The power block model is a very simple formula that considers the nominal conversion efficiency of the steam cycle, its part load behaviour and the parasitic losses of the power plant. The net electric power output of the plant is

$$
P_{\text {net }}=\dot{Q}_{\mathrm{SF}} \cdot \eta_{\text {nom }} \cdot\left[\frac{\dot{Q}_{\mathrm{SF}}}{\dot{Q}_{\mathrm{SF}, \mathrm{nom}}}\right]^{\mathrm{K}}-P_{\mathrm{Par}, \mathrm{SF}}-P_{\mathrm{Par}, \mathrm{PB}} \quad[\mathrm{W}] \text {, }
$$


being $\eta_{\text {nom }}$ the nominal efficiency of the power cycle and $\dot{Q}_{\mathrm{SF}, \mathrm{nom}}$ the rated nominal thermal power output of the solar field. The exponent $\kappa$ describes the partial load behaviour of the power cycle efficiency. $P_{\mathrm{Par}, \mathrm{SF}}$ and $P_{\text {Par,PB }}$ represent the parasitic electricity consumption of the solar field and of the power block, respectively. The parasitic losses are also a function of load. The model considers a minimum irradiation intensity of 200 $\mathrm{W} / \mathrm{m}^{2}$ for power block start-up. Efficiency and parasitic losses are calculated for three types of cooling systems, that is dry cooling system, evaporation cooling tower and once-through cooling. The resulting net power is integrated to the net annual solar electricity yield $E_{\text {year }}$ for each point of the map (Figure 7).

The simulation showed an acceptable accuracy, representing well the geometrical effects of the angle of incidence varying with time and place for all latitudes between 0 and $40^{\circ}$ North and South. A comparison to measurements at the original SEGS in California $(7,12)$ showed a very good qualitative and quantitative agreement with the actual physical behaviour of those plants (Figure 6). The achieved accuracy of the average daily energy yield of better than $\pm 5 \%$ was considered to be sufficient for the purpose of the first prototype of STEPS.

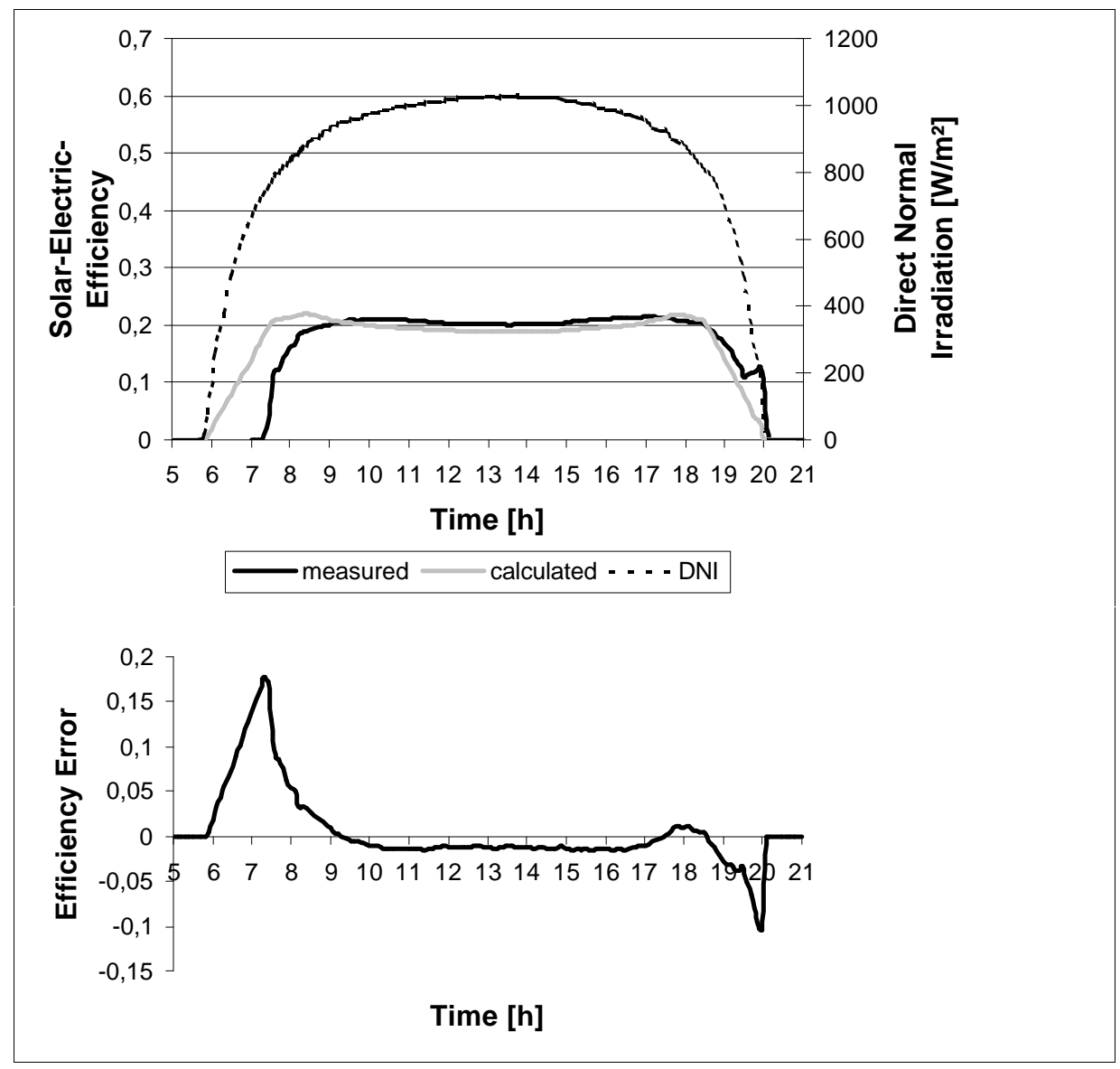

Figure 6: Measured and calculated overall net solar-to-electricity efficiency including parasitic losses of SEGS VI on July 1, 1997 (7). The original measured radiation data was used as input to the model. A considerable difference between the measured and the predicted efficiency occurs during start-up, as the model neglects the thermal inertia of the solar field and the power block (lower graph). In the real plant, part of the energy used for heating up in the morning is recovered during the day and in the evening. In this period, the model underestimates plant efficiency. Therefore, this source of error compensates itself to a large extend in the course of a day. As a consequence, the measured and calculated daily electricity yield differs by only $2 \%$.

Most of the parameters of the simulation model have been considered as constants. Further improvements of the performance model will be achieved in the future by considering the influence of varying ambient and operation temperatures. For example, ambient temperatures also can be derived from satellite data (2) and processed by the GIS. Dynamic start-up behaviour, thermal inertia of the solar field, wind effects, thermal energy storage and hybrid fuel-solar operation modes are other topics for future enhancement of the simulation model. 
Table 1: Selected properties of the LS-2 and LS-3 parabolic trough collectors

\begin{tabular}{|l|r|r|}
\hline & $\mathrm{LS}-2$ & $\mathrm{LS}-3$ \\
\hline Aperture & $5,00 \mathrm{~m}$ & $5,76 \mathrm{~m}$ \\
Length SCA(Solar Collector Assembly) & $48 \mathrm{~m}$ & $99 \mathrm{~m}$ \\
Distance between Rows & $12-15 \mathrm{~m}$ & $16-17 \mathrm{~m}$ \\
Reflecting Surface per SCA & $235 \mathrm{~m}^{2}$ & $545 \mathrm{~m}^{2}$ \\
Convection Loss Factor & $2 \mathrm{~W} / \mathrm{m}^{2} \mathrm{~K}$ & $2 \mathrm{~W} / \mathrm{m}^{2} \mathrm{~K}$ \\
Diameter of the Absorber Tube & $0,07 \mathrm{~m}$ & $0,07 \mathrm{~m}$ \\
Concentration Ratio & 72 & 82 \\
Reflectivity of Mirror & 0.93 & 0.93 \\
Coefficient of Absorption of Absorber Tube & 0,94 & 0,96 \\
Coefficient of Emission of Absorber Tube & 0,24 & 0,17 \\
Coefficient of Transmission of Mirror & 0.98 & 0.98 \\
Coefficient of Transmission of Glass Tube & 0,95 & 0,96 \\
Collector Peak Efficiency & $66 \%$ & $68 \%$ \\
\hline
\end{tabular}

\section{Cost Estimate}

The electricity $\operatorname{cost} C_{\mathrm{el}}$ of a solar thermal power station operating in solar-only mode depends mainly on its investment cost $I_{\text {plant }}$, the infrastructure cost for connecting the plant to roads and the public grid $I_{\text {inf }}$, the annual running expenses of operation and maintenance $C_{\mathrm{O} \& \mathrm{M}}$, the economic lifetime $n$, the mean capital interest rate $i$, and the net annual solar electricity yield $E_{\text {year }}$ at the respective site.

$C_{\mathrm{el}}=\frac{\frac{i \cdot(1+i)^{n}}{(1+i)^{n}-1} \cdot\left(I_{\text {plant }}+I_{\text {inf }}\right)+C_{\mathrm{O \& M}}}{E_{\text {year }}} \quad[\mathrm{USD} / \mathrm{kWh}]$

The sensitivity of the electricity cost to the variation of selected input parameters is given in Table 2 . Table 3 shows the most important economic parameters used as reference for the study on Northern Africa. Due to the influence on the power plant efficiency, the different types of cooling systems require different sizes of the solar collector and the corresponding investment in order to yield the same rated power of $200 \mathrm{MW}$.

Figure 8 shows the procedure of calculating the infrastructure cost from the distances to the nearest road, grid and cooling water source derived from the well known Digital Chart of the World (DCW). In this first version of STEPS, no distinction has been made between the different economic environments of the countries of the Maghreb. Specially the cost of infrastructure and personnel will vary strongly from country to country. Country specific parameters (country data base) and a more detailed calculation of the economic performance will be integrated in a future version of STEPS.

Table 2: Sensitivity of the electricity cost of a 200 MW SEGS in solar only mode (2)

\begin{tabular}{|l|c|}
\hline Parameter varied by e.g. + 100 \% & Relative $\mathbf{C}_{\mathrm{el}}$-Variation \\
\hline Annual Direct Normal Irradiation & -1.40 \\
Annual Cloud Index & -1.40 \\
Geometrical and Optical Efficiency & -1.35 \\
Overall Investment & +0.95 \\
Power Block Investment & +0.94 \\
Average Interest Rate & +0.53 \\
Annual Aerosol Optical Thickness & +0.41 \\
Thermal Losses & +0.31 \\
Insurance Cost & +0.08 \\
Cost of Operation \& Maintenance & +0.08 \\
Mean Salaries & +0.05 \\
Atmospheric Water Vapour & +0.04 \\
Atmospheric Ozone & +0.02 \\
\hline
\end{tabular}

Note: Values indicate relative sensitivities. An absolute $100 \%$ variation may not be realistic for some parameters. 
Table 3: Selected parameters of the economic model for Northern Africa

\begin{tabular}{|c|c|}
\hline Type of Power Plant & Parabolic Trough, LS-3 \\
\hline Capacity & $200 \mathrm{MW}$ \\
\hline \\
\hline using a dry cooling system & $1.228 \mathrm{~km}^{2}$ \\
\hline using an evaporation cooling tower & $1.124 \mathrm{~km}^{2}$ \\
\hline using a once-through cooling system & $1.075 \mathrm{~km}^{2}$ \\
\hline Required Land Area (cost free) & approx. 3 times solar collector area \\
\hline \multicolumn{2}{|l|}{ Plant Investment $\left(I_{\text {plant }}\right)$} \\
\hline using a dry cooling system & 460 Mio. USD \\
\hline using an evaporation cooling tower & 420 Mio. USD \\
\hline using a once-through cooling system & 405 Mio. USD \\
\hline \multicolumn{2}{|l|}{ Infrastructure Costs $\left(I_{\text {inf }}\right)$} \\
\hline per kilometer road & $185,000 \mathrm{USD}$ \\
\hline per kilometer high tension grid & $125,000 \mathrm{USD}$ \\
\hline per kilometer pipeline (once-through) & 2 Mio. USD \\
\hline per kilometer pipeline (evaporation) & 305,000 USD \\
\hline \multicolumn{2}{|l|}{ Operating Costs $\left(C_{\text {O\&M }}\right)$} \\
\hline Personnel & 2.7 Mio. USD per year \\
\hline Operation \& Maintenance & $1 \%$ of Investment per year \\
\hline Insurance & $1 \%$ of Investment per year \\
\hline Economic Lifetime (n) & 25 years \\
\hline Average Interest Rate (i) & $8 \%$ \\
\hline
\end{tabular}

The resulting solar electricity cost is displayed in Figure 9. Figures 7 and 9 show the large technical and economic potential of solar power generation in North Africa. Theoretically, on less than $1 \%$ of the suitable area in North Africa, the total 1997 world electricity demand of 12,000 TWh/year could be generated at a cost of less than 12 cents/kWh (price level 1998, solar only operation, see also Table 4). According to the remaining potential of cost reduction of solar thermal power technology, this cost will come down within a decade to less than 6 cents/kWh (8),(9). With available support from the World Bank and in hybrid operation mode, a competitive electricity cost can already be achieved today.

\section{Conclusions}

STEPS enables the computer based assessment of solar irradiation, geographic frame conditions, requirements of infrastructure and the expected electricity potential and cost of solar thermal power stations for large regions, providing results with high spatial and temporal resolution. The tool can be used for the assessment, evaluation and ranking of sites of solar thermal power plant projects, giving project developers, governments, intergovernmental institutions and other decision makers a well founded basis for planning and designing the build out of solar power capacity world wide. The tool has been applied successfully on North Africa, showing the large technical and economical potential of solar thermal power in this region.

It must be pointed out that the results of the first prototype of STEPS shown here should not be used directly for investment decisions, as they only represent one possible power plant configuration and are based on low resolution and partially insufficient input data (e.g. no radiation climatology was used). They are primarily meant for demonstrating the concept.

For in-depth analysis of a country's solar thermal power potential and for detailed site ranking on a feasibility study level, STEPS is presently enhanced by an extensive country data base, further GIS data on natural and political risks, soils, hydrology and natural reserve areas, a more sophisticated and variable performance model, a more accurate method of cloud and aerosol assessment, a long term radiation climatology and other issues. With the recent Space Shuttle Radar Topography Mission, higher resolution topographic data is now available for more detailed siting purposes. 


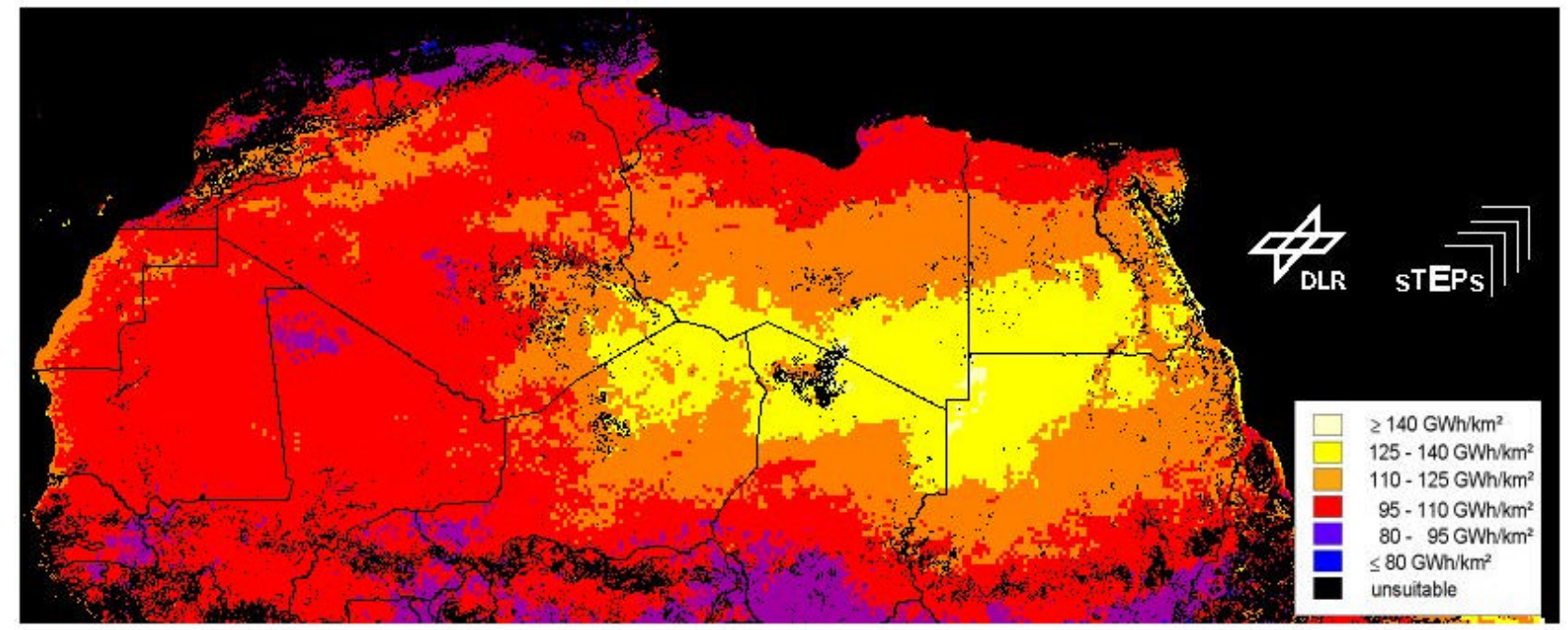

Figure 7: North Africa - Annual solar electricity yield per $\mathbf{k m}^{2}$ of land area.
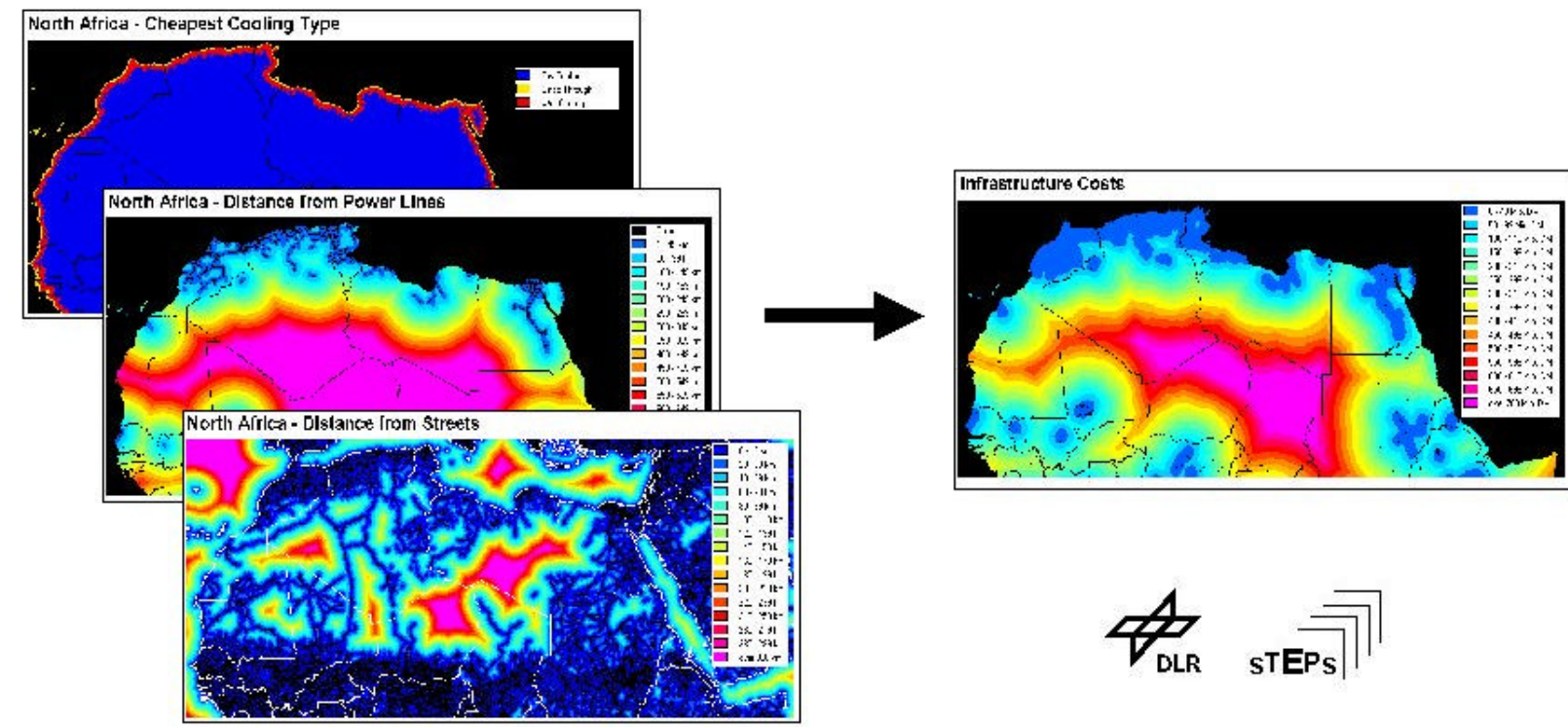

Figure 8: Calculation of infrastructure costs from the distances to roads, grids and cooling water.

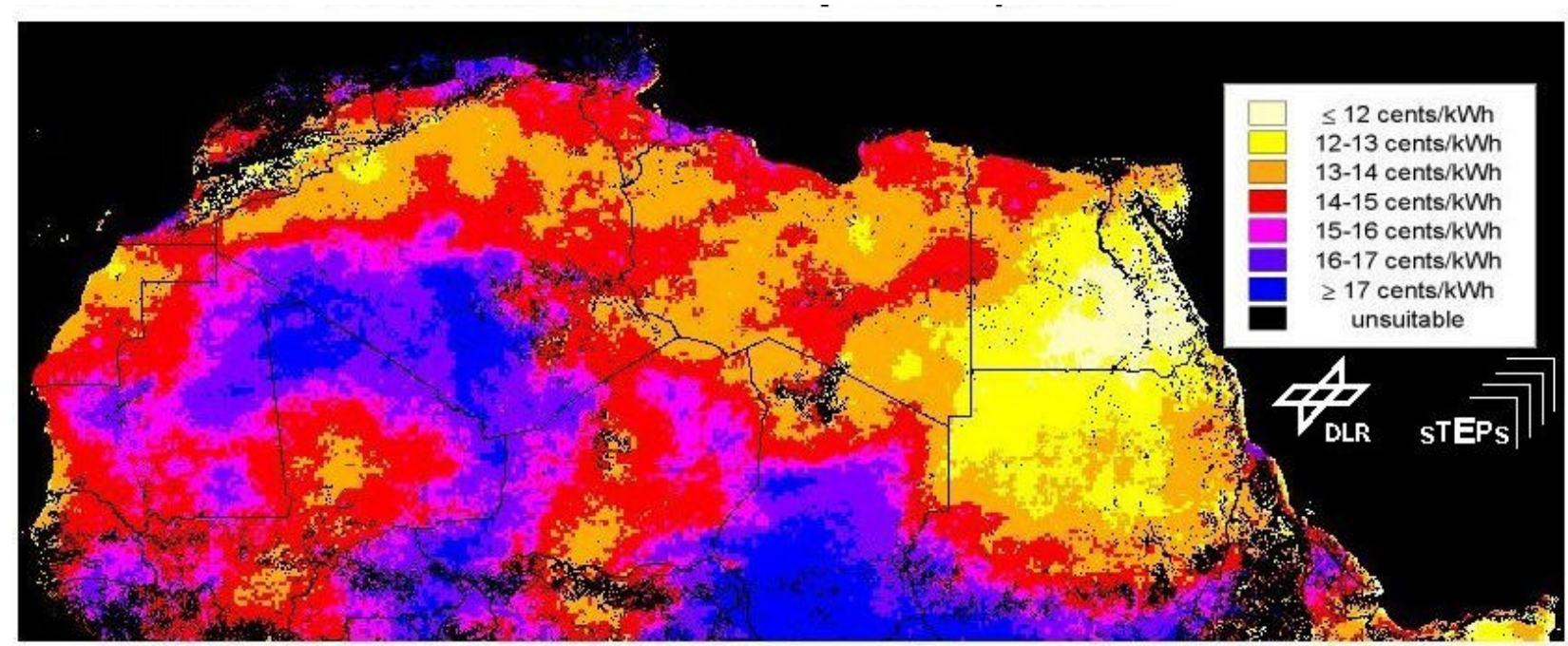

Figure 9: North Africa - Solar electricity cost per kWh. (200 MW SEGS, solar only, price level 1998) 
Table 4: Ranking of areas by the solar thermal power generation cost per $\mathrm{kWh}$ in North Africa

\begin{tabular}{|c|r|r|}
\hline \multicolumn{2}{|l|}{ Total size of the analysed area in North Africa } & \multicolumn{2}{|c|}{14.3 Mio. $\mathrm{km}^{2}$} \\
\hline $\begin{array}{c}\text { Suitable area with respect to land cover and land slope } \\
\text { This area splits into the following categories: }\end{array}$ & $\begin{array}{c}\text { Potential of Power Generation } \\
\text { in TWh }\end{array}$ \\
\hline $\begin{array}{c}\text { Power Generation Costs } \\
\text { in cents/kWh }\end{array}$ & $\begin{array}{r}\text { Available Area } \\
\text { in } 1.000 \mathrm{~km}^{2}\end{array}$ \\
\hline$\leq 12$ & 297.1 & 37,994 \\
\hline $12-13$ & 1107.9 & 138,047 \\
\hline $13-14$ & 2999.4 & 339,939 \\
\hline $14-15$ & 3896.9 & 412,603 \\
\hline $15-16$ & 1986.3 & 203,575 \\
\hline $16-17$ & 1340.2 & 135,973 \\
\hline$\geq 17$ & 980.6 & 93,425 \\
\hline Total & $\mathbf{1 2 , 6 0 8 . 4}$ & $\mathbf{1 , 3 6 1 , 5 5 6}$ \\
\hline
\end{tabular}

\section{References}

(1) R.E. Bird, A simple solar spectral model for direct-normal and diffuse horizontal irradiation, Solar Energy Vol. 32, No. 4, pg. 461-471 (1984).

(2) H. Broesamle, Solar thermal power stations. Localization and assessment of the potential with the planing tool STEPS, Doctoral thesis, University of Vechta 1999 (in German).

(3) P. Köpke, M. Hess, I. Schult, E.P. Shettle, Global Aerosol Data Set, Max Planck Institute for Meteorology, Report No. 243, Hamburg 1997.

(4) H. Mannstein, H. Broesamle, C. Schillings, F. Trieb, Using a METEOSAT cloud index to model the performance of solar thermal power stations, Proceedings of the EUMETSAT Meteorological Satellite Data Users Conference, Copenhagen 1999.

(5) J.S. Olson, Global ecosystem framework-definitions, USGS EROS Data Centre Internal Report, Sioux Falls, SD, 37 S, 1994.

(6) C. Schillings, Calculation of the direct-normal irradiation for the using in solar thermal power stations. Application of a physical clear-sky model using satellite data, Masters thesis, University of Bonn 1999.

(7) G.E. Cohen, D.W. Kearney, H.W. Price, Performance History and Future Costs of Parabolic Trough Solar Electricity Systems, Proceedings of the 9th International Symposium on Solar Thermal Concentrating Technologies, Odeillo, France, 1998, Journal of Physics IV, EDP Sciences 1999.

(8) Enermodal Engineering Ltd, Cost Reduction Study for Solar Thermal Power Plants, World Bank/GEF, Washington D.C., May 5, 1999.

(9) F. Trieb, Competitive Solar Thermal Power Stations until 2010 - The Challenge of Market Introduction; 9th International Symposium on Solar Thermal Concentrating Technologies, Odeillo, France, 1998, Journal of Physics IV, EDP Sciences 1999.

(10) Personal correspondence with M. Hess, 1998.

(11) M. Iqbal, An Introduction to Solar Radiation. Academic Press. Toronto, 1983.

(12) V.E. Dudley, G.J. Kolb, A.R. Mahoney, T.R. Mancini, C.W. Matthews, M. Sloan, D. Kearney, Test Results of SEGS LS-2 Solar Collector, Sandia Report SAND94-1884, Albuquerque, 1994. 